\section{Commentary: Pharmacologic induction of spinal cord ischemic tolerance: Game changer in thoracoabdominal aneurysm repair?}

Andreas Habertheuer, MD, PhD, and Ashraf A. Sabe, MD

Spinal cord ischemia remains a dreaded and yet incompletely understood complication of thoracoabdominal aortic aneurysm repair. Protagonists are (1) loss of endarterial perfusion via direct ligation of intercostals; (2) ischemia-reperfusion phenomenon during crossclamp of aortic segments and subsequent restoration of flow; and (3) creation of watershed territories with perfusion through intercostal patches and collaterals from above and below the resected segment. Aortic surgeons have multiple strategies aimed at reducing the risk of paraplegia. These focus on intraoperative monitoring of somatosensory- or motorevoked potentials, facilitating early detection of spinal cord ischemia as well as perioperative measurement and potential drainage of cerebrospinal fluid, allowing cord perfusion by keeping arterial pressure and cerebrospinal fluid pressure at an equilibrium. Operative strategies include staged repair to minimize ischemic cord segments, restoring cord perfusion by reimplanting intercostals, or maintaining distal perfusion using left heart bypass. Despite this, paraplegia occurs at a rate of $2.9 \%$ to $16.0 \%$, with the greatest risk unsurprisingly reported for extent II thoracoabdominal aneurysms. ${ }^{1,2}$ With rates of neurologic complications plateauing in recent years, exploration of new avenues for protection remains paramount.

\footnotetext{
From the Division of Cardiac Surgery, Department of Surgery, Brigham and Women's Hospital, Harvard Medical School, Boston, Mass.

Disclosures: The authors reported no conflicts of interest.

The Journal policy requires editors and reviewers to disclose conflicts of interest and to decline handling or reviewing manuscripts for which they may have a conflict of interest. The editors and reviewers of this article have no conflicts of interest.

Received for publication Oct 7, 2021; revisions received Oct 7, 2021; accepted for publication Oct 7, 2021; available ahead of print Oct 14, 2021.

Address for reprints: Ashraf A. Sabe, MD, Division of Cardiac Surgery, Brigham and Women's Hospital, 75 Francis St, Boston, MA 02115 (E-mail: asabe@partners. org).

J Thorac Cardiovasc Surg 2023;165:e100-1

$0022-5223 / \$ 36.00$

Copyright (c) 2021 by The American Association for Thoracic Surgery

https://doi.org/10.1016/j.jtcvs.2021.10.010
}

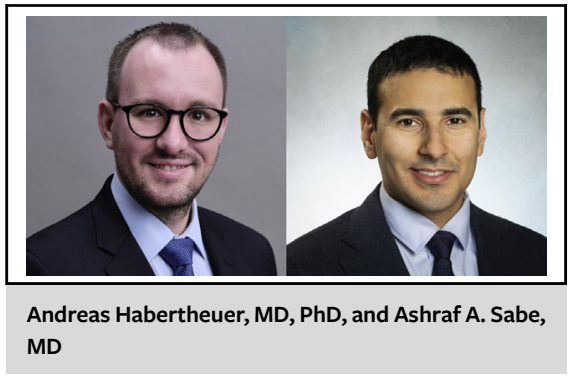

CENTRAL MESSAGE

Spinal cord ischemia remains a dreaded complication during repair of thoracoabdominal aneurysms. Exploration of pharmacologic induction of spinal cord ischemic tolerance remains largely uncharted.

In this issue of the Journal, Ikeno and colleagues ${ }^{3}$ explore a novel strategy of pharmacologic induction of spinal cord ischemic tolerance. The group has an impressive record in delineating the potential role of mitochondrial ATPsensitive potassium channel (KATP) in improving cellular tolerance to ischemia. ${ }^{4-6}$ The authors use a murine model of spinal cord ischemia to evaluate neuroprotective effects of direct versus indirect activation of the KATP channel. In their elegant study design, they compared neuroprotective effects of nicorandil, a direct and indirect KATP activator via direct channel agonism as well as indirect stimulation via release of nitric oxide, and diazoxide, a direct KATP channel activator-both with and without the addition of cPTIO, a NO scavenger. Compared with controls, there was significant improvement in motor functional outcomes and neuron cell viability in the nicorandil group. Diazoxide alone as well as coadministration of nicorandil or diazoxide with cPTIO resulted in attenuation of ischemic protective effects. These results suggest that the trick might lie in combined direct and indirect channel activation.

As the authors note, there are limitations. A juvenile small animal model cannot reliably reproduce the complexity of chronic aortic and microvascular disease. The study does not account for the critical postoperative course, where even short bouts of hypotension and alterations of cerebrospinal pressure may lead to irreversible neuronal damage many hours after repair. Management of thoracoabdominal aneurysms is complex, and the spinal 
cord remains at risk beyond the initial ischemia trigger. KATP channels are inward rectifiers, and opening thereof provides ischemic protection via hyperpolarization and suppression of neuronal activity in the classic preconditioning model. Both drug dose-dependent responses as well as time point of administration might further impact treatment efficiency. Additional mechanistic understanding of KATP downstream pathways is warranted to ultimately delineate its role.

Nevertheless, the aforementioned results are remarkable. Improving tolerance of the spinal cord to ischemic insults on a cellular level has the potential to be a game changer and may become an essential tool in the arsenal of the aortic surgeon. We look forward to hearing more from this group, and others, as they strive to carry work like this bench to bedside.

\section{References}

1. Coselli JS, Green SY, Price MD, Zhang Q, Preventza O, de la Cruz KI, et al. Spinal cord deficit after 1114 extent II open thoracoabdominal aortic aneurysm repairs. J Thorac Cardiovasc Surg. February 12, 2019 [Epub ahead of print].

2. Coselli JS, LeMaire SA, Preventza O, de la Cruz KI, Cooley DA, Price MD, et al Outcomes of 3309 thoracoabdominal aortic aneurysm repairs. J Thorac Cardiovasc Surg. 2016;151:1323-37.

3. Ikeno Y, Ghincea CV, Roda GF, Cheng L, Aftab M, Meng X, et al. Direct and in direct activation of the ATP-sensitive potassium channel to induce spinal cord ischemic metabolic tolerance. J Thorac Cardiovasc Surg. 2023;165:e90-9.

4. Caparrelli DJ, Cattaneo SM II, Bethea BT, Shake JG, Eberhart C, Blue ME, et al. Pharmacological preconditioning ameliorates neurological injury in a model of spinal cord ischemia. Ann Thorac Surg. 2002;74:838-44; discussion 844-5.

5. Yamanaka K, Eldeiry M, Aftab M, Mares J, Ryan TJ, Meng X, et al. Optimized induction of beta common receptor enhances the neuroprotective function of erythropoietin in spinal cord ischemic injury. J Thorac Cardiovasc Surg. 2018; 155:2505-16.

6. Roseborough G, Gao D, Chen L, Trush MA, Zhou S, Williams GM, et al. The mitochondrial K-ATP channel opener, diazoxide, prevents ischemia-reperfusion injury in the rabbit spinal cord. Am J Pathol. 2006;168:1443-51.
See Article page ego.

\section{Commentary: A little help from the bench to cut risk of paraplegia?}

\author{
Monika Halas, MD, and Joseph S. Coselli, MD ${ }^{\mathrm{a}, \mathrm{b}, \mathrm{c}}$
}

Although open aortic repair is associated with substantial postoperative complications, spinal cord deficit (ie, paraplegia and paraparesis) may be the most devastating one. Regarding Crawford's lifetime experience with 1509 thoracoabdominal aortic aneurysm (TAAA) repairs, as presented

\footnotetext{
From the a Division of Cardiothoracic Surgery, Michael E. DeBakey Department of Surgery, Baylor College of Medicine; ${ }^{b}$ Department of Cardiovascular Surgery, Texas Heart Institute; and ${ }^{\mathrm{c}} \mathrm{CHI}$ St Luke's Health—Baylor St Luke's Medical Center, Houston, Tex.

Dr Coselli's work is partly supported by endowment by the Cullen Foundation. Disclosures: Dr Coselli consults for, receives royalties and a departmental educational grant from, and participates in clinical trials for Terumo Aortic; consults and participates in clinical trials for Medtronic Inc, Edwards Lifesciences, and W. L. Gore \& Associates; and serves as a coinvestigator for CytoSorbents. Dr Halas reported no conflicts of interest.

The Journal policy requires editors and reviewers to disclose conflicts of interest and to decline handling or reviewing manuscripts for which they may have a conflict of interest. The editors and reviewers of this article have no conflicts of interest.

Received for publication Sept 10, 2021; revisions received Sept 10, 2021; accepted for publication Sept 13, 2021; available ahead of print Sept 16, 2021.

Address for reprints: Joseph S. Coselli, MD, Division of Cardiothoracic Surgery, Michael E. DeBakey Department of Surgery, Baylor College of Medicine, One Baylor Plaza, BCM 390, Houston, TX 77030 (E-mail: jcoselli@bcm.edu).

J Thorac Cardiovasc Surg 2023; 165:e101-2

$0022-5223 / \$ 36.00$

Copyright $(2021$ by The American Association for Thoracic Surgery

https://doi.org/10.1016/j.jtcvs.2021.09.020
}

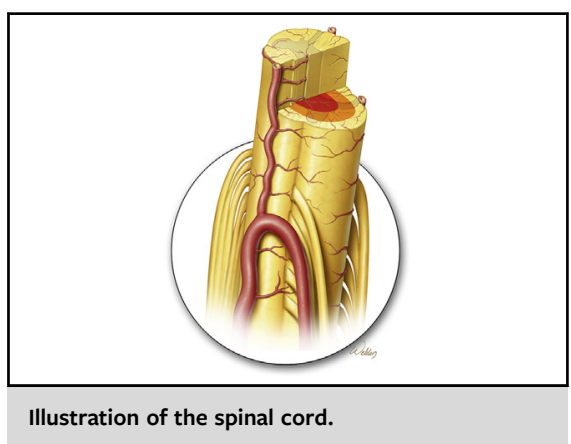

CENTRAL MESSAGE

Preventing spinal cord deficit requires a multimodal approach.

in the late 1990s by Svensson and colleagues, ${ }^{1}$ the rate of postoperative spinal cord deficit was a staggering $31 \%$ after the most extensive form of such repair, the Crawford extent II TAAA repair. Since the Crawford era, the rates of spinal cord deficit have dramatically decreased; rates of temporary and permanent spinal cord deficit were $2.4 \%$ and $5.4 \%$, respectively, across all extents of TAAA repair, and for extent II repair, the rate of permanent spinal cord deficit was $8.0 \%{ }^{2}$ How were surgeons able to reduce the 